\title{
GROUP INFIUENCES ON PROBABILITY JUDGMENTS CONCERNING SOCIAL AND POLITICAL CHANGE ${ }^{1}$
}

\author{
HELMUT LAMM AND GISELA TROMMSDORFF \\ Universität Mannbeim, West Germany
}

\begin{abstract}
Summary.-This study was intended to inquire into the generality of groupinduced extremization (shift away from the neutral, middle point of a given response scale). The stimulus task for subjects was to estimate the probability that certain desired social, political, or economic conditions would exist by the year 2000. Another purpose of this study was to test the generality of the discussion-induced shift toward pessimism found in a previous study. Using nine discussion groups (size 3 or 4 ) and 13 control subjects (simple test-retest), the following findings we:e obtained. (1) Group means shifted toward higher extremity after discussion. (2) There was no shift when the extremity of group members' individual positions were compared. (3) The control subjects shifted toward less extreme judgments, and their judgmental confidence decreased. (4) No group shift toward pessimism was obtained. The discussion centers on subsidiary (correlational) evidence suggesting one cause of this group extremization was the disproportionate influence of extreme group members.
\end{abstract}

Moscovici and Zavalloni (1969) were the first to allude to tendency toward extremization of attitude as a result of group interaction (discussion). Such findings were remarkable as they appeared to contradict the generally accepted theory that a group context leads to a convergence of the positions (Allport, 1924; Sherif, 1935).

Research carried out by Andrews and Johnson (1971), Cvetkovich and Baumgartner (1973), Doise (1969), Moscovici and Zavalloni (1969), Moscovici, Doise, and Dulong (1972), Moscovici and Lecuyer (1972), Moscovici, Zavalloni, and Louis-Guérin (1972), Moscovici, Zavalloni, and Weinberger (1972), Moscovici and Nève (1973), Fraser, Gouge, and Billig (1971), Gouge and Fraser (1972), Myers and Bishop (1970, 1971), Rabbie and Visser (1972), McCauley (1972), and Paicheler and Bouchet (1973), also demonstrated groupinduced extremization. They all, by means of a variety of stimulus tasks, indicated that group positions were more extreme than the average of the group members' initial positions. It was irrelevant whether the discussion concerned political or social opinions, risk-relevant material or person perception: after group interaction the positions became more extreme.

\footnotetext{
${ }^{1}$ This study was conducted at the Sonderforschungsbereich 24 für Sozial- und Wirtschaftspsychologische Entscheidungsforschung, Universität Mannheim (FRG), financed by the Deutsche Forschungsgemeinschaft, with support from the Government of Baden-Württemberg. We would like to thank, in particular, Edith Rost-Schaude for her help in running subjects. The computer program (MIS-2-) used for the data analysis stems from Dr. Gebhardt of DRZ Darmstadt.
} 
Group's extremization:-All the cited experiments calculated the initial extremity as the distance of the group average from the neuiral (middle) point of the scale. This extremity score was then compared with the corresponding extremity score after discussion to establish the extremity shift. We, however, question this method of assessing extremization: to take the initial ratings of the (future) group members as the average (and from thence the extremity ratings) suggests the fiction of a group position which does not appear to us to be psychologically justified.

Individual's extremizetion. -The initial extremity (before group participation) is based on the (average of the) extremity of each (future) member's position. In this way-contrary to the above-described "extremization by a group"-the variation of the individual participants around the neutral point of the scale is taken into consideration.

Kogan and Wallach (1966) first tested whether such an individual extremization occurred after group interaction. However, they were not able to demonstrate such an extremization effect. On the contrary, a trend towards lower extremity was shown. ${ }^{2}$ McCauley (1972) also discovered no individual but a group movement to extremization. Up to now, only Myers and Bishop (1971) could demonstrate an individual extremization (but only a very slight one). It is to be emphasized that these authors selected only such items for discussion in which one pole was "dominant," that is, the majority of the group members tended towards one pole already before the discussion.

\section{Attempts to Explain}

Up to now an explanation of the causes of extremization by a group has not been found. The various attempts at an explanation partly overlap and complement each other (see Lamm, Trommsdorff, \& Rost-Schaude, 1973). On the whole, one can make a distinction between the "majority thesis," the "commitment thesis" and the "extremist's influence thesis."

Majority thesis.-According to Fraser, Gouge, and Billig (1971), a skewed distribution is one possible condition for extremization in a group. Similarly, Andrews and Johnson (1971) argue for the "climb-on-the-bandwagon-effect." Recently, Moscovici and Nève (1973) found that group extremization was most frequently a result of a minority changing toward the majority. Lamm, Trommsdorff, and Rost-Schaude (1973) conclude in their analysis that groupinduced extremization mainly is the result of a minority shift towards the majority.

Commitment thesis.-Moscovici and Zavalloni (1969) claim that group interaction concerning a relevant, i.e., subjectively important, stimulus brings about an increased feeling of commitment of the group members towards their ${ }^{2}$ On re-analysis of the data of Kogan and Wallach (1966), Doise (1971) found an in-
crease in group extremity. 
original positions. Through group interaction (a) the involvement of the discussants, (b) the subjective ceriaincy, and/or (c) the subjective importance of the task (s.imulus material) is increased. As Moscovici and Nève (1973) argue, group extremization takes place in direction of the social norm which emerges from the preconsensus position of the subejcts. Thus, group-induced extremization can be seen as a product of "normative commitment" through group discussion.

The extremist's influence thesis.--This interpretation states that the group members whose (initial) positions are relatively extreme can exert a relatively large influence on the group. Doise (1969) found some exidence for this proposition, namely, that the group most often adjusted its positions to those of the extremist. It is our intention in the present study to add relevant data to this thesis.

Aims of Present Study

Generality of the extremization phenomenon.-It is to be examined whether a group-induced extremizarion also occurs in probability estimates. On the basis of recent research and our theoretical statements (see Lamm, Trommsdorff, \& Rost-Schaude, 1973), we expected group discussions to lead to extremization for a group but not for an individual.

Explanation of group-induced extremization.-Here we want to test various relationships which are pointed out in the above "commitment thesis," especially the relationship between certainty, density of verbal interaction, and extremization.

Discussion-induced increase in pessimism.-Lamm, Trommsdorff, and Kogan (1970) found that group discussions on probabilities lead to enhanced pessimism (lower chance of success in a fictional action involving risk). The authors assumed that the above-mentioned result was caused by the increased tendency in the group context for the members to concentrate on "problematic" aspects, i.e., to suggest arguments against the occurrence of the desired goal.

In our study it will be tested whether the above-mentioned increase in pessimism (pessimistic shift) also occurs in the case of probability estimates which (a) refer to the actual future of the participants (in contrast to the fictional situations in our earlier research), and (b) concern future states of affairs (in contrast to risky actions with success and failure as the sole possible results, as was the case in the earlier study). Consequently, we are here dealing with additional data to examine the generality of a group-induced pessimistic shift.

\section{Instrument}

\section{METHOD}

As stimulus task, a list was presented which consisted of 14 items from the Inventory of Future Events (Zukunftsinventorium). The inventory con- 
tains 36 statements each of which describes a desirable condition which could exist by the year 2000. These items were constructed on the basis of students' statements concerning their hopes for the future of West Germany (Lamm, unpublished data).

The 14 items of the list used in the present study refer to various areas of public life: economy, domestic and foreign policy, social circumstances, education, e.g., Item 1: "All wage-earners will work 30 hours or less a week." Item 14: "Israelis and Arabs will live in peace together."3

\section{Subjects}

Male students $(n=46$ ) at the Universität Mannheim took part in the experiment and received DM 3.50 an hour.

\section{Experimental Procedure}

In the first meeting, each subject gave the following two responses to each of the 14 items: (a) an estimate of probability that the particular statement would apply in the year 2000 , i.e., that the particular change would have come about by that time (the estimates were to be given as percentages between $0 \%$ and $100 \%$ ) and (b) a statement of confidence that this estimated probability was correct ("in consideration of the information available at present"). The degree of confidence was rated on a scale ranging from 1 (extremely uncertain) to 7 (completely certain).

In the second meeting, which took place a few months later, discussion groups were formed (at random) or subjects individually participated in a simple retest.

Discussion groups.-A total of 9 discussion groups were formed, six groups of four subjects and three groups of three subjects. The participants were asked to discuss each of the 14 items for a maximum of $7 \mathrm{~min}$. and then come to a joint probability estimate. If deadlock occurred-that is, if a unanimous decision was not made within $7 \mathrm{~min}$ - - each participant stated the position closest to those of the other group members with which he was able to agree. The experimenter calculated the group average and asked the group members to record it as the group "decision."

During the discussions the experimenter noted the following: (1) Length of discussion: A stop watch was used to time the discussion from the first "verbal act" to the agreement reached by the participants. (2) Verbal acts: Each contribution to the discussion which was not interrupted by one of the other participants was registered as a verbal act (except 1-word exclamations such as "but," "hm," etc; on the other hand, statements of agreement or of rejection,

3The 14 items only reflected desirable future states of being. The average desirability was 6.83 per item as measured on a 9-point scale $(1=$ completely indifferent . . . $9=$ extremely desirable). (Ratings by the 46 subjects of the present study after the last measurement.) 
such as "yes," "no" were registered as a verbal act). The length of the verbal acts was not taken into consideration. (3) Interruptions: When a group member interrupted another one, that was registered as an interruption and as a new verbal act of the subject. (4) Initiative of discussion: For each discussion, it was noted who started the discussion. At the end of all group discussions, each subject stated how confident he was of the probability estimates.

The hitherto-completed work was then collected by the experimenter and the subjects were again requested to note down their individual probability estimates (third measurement). Finally the participants ranked each other in terms of persuasiveness.

Individual (control) condition.-In the second meeting (retest), 13 control subjects worked on the list of future events individually as in the first meeting. First, they made probability estimates; they then made confidence ratings.

RESULTS

\section{Shifts From First To Second Measurement}

In the discussion groups there were no significant directional shifts in the probability estimates. The individual extremity of the estimates-the absolute difference of each test subject from the central point of the scale (50)-also did not change from the first to the second and third measurement. However, the group's extremity from the first to second ratings increased significantly: the group averages became more extreme $(t=5.65$, $d f=8, p<.001$; twotailed $t$ test for dependent samples). Judgmental certainty did not change from the first to the second measure.

In the individual (control) condition, as expected, no increase in pessimism or in extremity occurred. The control subjects became less confident ( $t$ $=3.72, d f=12, p<.01)$ and less extreme $(t=2.66, d f=12, p<.05)$.

\section{Correlations Between Dependent Variables}

In the individual (control) condition, no significant correlations (Pearson) were found between the dependent variables. In the following, we will only present Pearsonian correlations of discussion groups, based on group scores $(N=9)$. The correlations between the individual scores of the group condition $(N=33)$ will be treated in the discussion section.

The individual extremity in the discussion groups correlated positively with the judgmental certainty (first measurement: $r=.76, p<.02$; second measurement: $r=.64, p<.10$ ). Group extremity correlated (slightly) with judgmental certainty (first measurement: $r=.56$, n.s.; second measurement: $r$ $=.59, p<.10)$. An increase in judgmental certainty was also linked with an increase in extremity (individual extremity: $r=.78, p<.02$; group extremity: $r=.67, p<.05)$.

The greater the pre-discussion group extremity, the shorter were the group discussions $(r=-.79, p<.02)$, the fewer verbal acts were emitted $(r=$ 
TABLE 1

MEAN VALUES AND STANDARD DEVIATIONS

\begin{tabular}{|c|c|c|c|c|}
\hline & \multicolumn{2}{|c|}{$\begin{array}{c}\text { Discussion } \\
\text { groups } \\
\left(N^{T}=9\right)\end{array}$} & \multicolumn{2}{|c|}{$\begin{array}{l}\text { Individual } \\
\text { condition } \\
(N=13)\end{array}$} \\
\hline & $M$ & $S D$ & $M$ & $S D$ \\
\hline \multicolumn{5}{|l|}{ Probability ${ }^{2}$} \\
\hline 1st measurement & 4.82 & 0.74 & 5.01 & 1.19 \\
\hline 2nd measurement & 4.57 & 1.34 & 4.59 & 0.63 \\
\hline 3rd measurement & 4.72 & 1.12 & & \\
\hline 1 st-2nd measurement & 0.25 & 1.38 & 0.42 & 1.11 \\
\hline \multicolumn{5}{|l|}{ Certainty ${ }^{2}$} \\
\hline 1st measurement & 5.04 & 0.48 & 4.96 & 0.54 \\
\hline 2nd measurement & 4.90 & 0.38 & 4.51 & 0.47 \\
\hline 1st $-2 \mathrm{nd}$ measurtment & 0.14 & 0.49 & $0.45^{*}$ & 0.42 \\
\hline \multicolumn{5}{|l|}{ Individual's Extremity ${ }^{3}$} \\
\hline 1st measurement & 2.82 & 0.43 & 2.76 & 0.42 \\
\hline 2nd measurement & 2.85 & 0.62 & 2.37 & 0.51 \\
\hline 3 rd measurement & 2.89 & 0.59 & & \\
\hline 1 st -2 nd measurement & -0.03 & 0.50 & $0.39^{*}$ & 0.50 \\
\hline \multicolumn{5}{|l|}{ Group's Extremity } \\
\hline 1st measurement & 1.90 & 0.61 & & \\
\hline 2nd measurement & 2.79 & 0.66 & & \\
\hline 3rd measurement & 2.54 & 0.38 & & \\
\hline $1 \mathrm{st}-2 \mathrm{nd}$ measurement & $-0.89 t$ & 0.45 & & \\
\hline
\end{tabular}

Note.-The scores are averaged over the 14 items.

${ }^{1}$ Probability estimates from $0(=0 \%)$ to $10(=100 \%)$.

${ }^{2}$ Certainty ratings from $1=$ extremely uncertain to $7=$ completely certain.

${ }^{3}$ Per item, distance of subject from 50.

"Pet item, distance of the group average from 50 .

${ }^{*} p<.05 ; \dagger p<.001 ;$ two-tailed $t$ tests for dependent samples.

$-62, p<.10)$, and the less did participants interrupt each other $(r=-.59$, $p<.10$ ). Similar correlations, or a trend in this direction, were found regarding the second and third probability measurements. ${ }^{4}$ However, there were no significant correlations to be found among the interaction characteristics, including an index of "interaction density" (number of verbal acts divided by the length of the discussions), and shift to extremity.

\section{Extremization and Its Explanation}

\section{Discussion}

Further evidence of group extremization has been demonstrated in the present study, concerning probability estimates as to whether future events or situations will occur or not.

Interaction characteristics and extremization.-We could not support the

"The discussion characteristics intercorrelated positively (length of discussion and number of verbal acts: $r=.83, p<.01$; number of verbal acts and number of interruptions: $r=.60, p<.10)$. 
hypothesis that length and intensity of discussions are related to an increase in extremity. Moscovici, I)ise, and Dulong (1972), on the other hand, reported greater extremization under conditions of unrestricted (and presumably more intensive) than under restricted group interactions. At this point, one must remember that in this study of Moscovici, et al. (1972) differences between experimental conditions were tested whereas the present study involves only correlative results.

Group's extremity, judgmental confidence, and extremization.-The positive correlations between the group's extremity and confidence scarcely aid us in the explanation of the increase in extremity of a group.

Moscovici and Zavalloni (1969) assumed that the judgmental certainty of the group members was increased by group interaction. We were not able to confirm this assumption. However, there was a significant positive correlation between the increase in extremity and the increase in judgmental certainty from the first and second tatings. This result is not surprising on taking into consideration the above-mentioned correlations between extremity and certainty (in the first as well as the second measurement).

Comparing the discussion and individual conditions, it can be shown that persons tend to be more certain after group discussions than individuals are after the retest $(t=1.95, d f=20, p<.05$; one-tailed $t$ test for independent samples). This change is associated with lesser certainty of the subjects in the individual condition. Possibly, this decrease in judgmental certainty derives from the subjects' tendency to become "more cautious" in their estimates when asked a second time for their assessments. In the individual condition, subjects only could rely on their personal experiences which, for this-kind of stimulus material, could not give much cognitive support for the correctness of their judgments. In the group condition, on the other hand, subjects could provide each other with judgmental support which at least helped to maintain the original level of certainty. It may be plausibly assumed that, for this kind of judgmental material, subjects have to rely on external rather than on internal support (see Upmeyer \& Schreiber, 1972).

Participants attributes and extremization.-Persuasiveness and individual extremization correlate negatively $(r=.61, d f=31, p<.01)$. Those discussants who appeared as most convincing changed their positions the least; they themselves were hardly influenced, but they influenced others. This influence may derive from the way these members deliver their contributions during the discussions, i.e., they argue for their positions more confidently. The latter is supported by the positive correlation between extremity for individuals and certainty on the first measurement $(r=.45, d f=31, p<.01)$.

Non-occurrence of Individual's Extremization

Extremization of individual positions' (in contrast to group positions or 
averages) did not occur in this experiment. Thus the assumption is confirmed here that the occurrence of extremization by an individual, as demonstrated only in one study ( see Myers \& Bishop, 1971), can be ascribed to the special conditions prevailing in the experiment of the above-mentioned authors. Myers and Bishop (1971) only used such items for which the average of the initial positions of the sample was always one point or more away from the neutral scale value on a 7 -point scale. In the present study, on the other hand, the items had been chosen partly because the various distances from the neutral scaling point were, on the average, tepresented to the same extent. The two "most extreme" items were $21.5 \%$ and $74.7 \%$, the "most neutral" item was $48.5 \%$.

Thus, the individual's extremization recorded by Myers and Bishop (1971) which could not be supported in three other experiments (Kogan \& Wallach, 1966; McCauley, 1972; this study) must be considered as an exceptional result.

It is to be noticed that an individual's extremization could be deduced from the "commitment thesis;" due to the group experience discussants become increasingly involved in their positions, and, consequently, discussants defend their positions more unconditionally and thus more extremely. Thus, the lack of any individual's extremization in this study (and other research) represents a non-confirmation of the "commitment thesis."

This study, however, suggests that individuals, without showing any increase in extremity, make more extreme judgments after they have discussed their positions than subjects who make the judgments for a second time without intervening group discussions $(t=1.88, d f=20, p<.05$; one-tailed $t$ test for independent samples). (The initial positions of the discussants and the control subjects in the individual condition did not differ from each other significantly.)

\section{Optimism/Pessimism}

An important result of this study is that group discussion did not lead to an increase in pessimism. The pessimistic shift reported by Lamm, Trommsdorff, and Kogan (1970) was not replicated here. This was not due to the relatively small number of groups. Only 9 groups were tested in the study of Lamm, et al. (1970) and the effect was significant. One may assume that the pessimistic shift might have been caused by a peculiarity in the stimulus task and/or the test situation. In that work, the so-called Choice Dilemmas were used (see Kogan \& Wallach, 1964); fictional situations in which a decision had to be made were briefly described, and the subjects had to assess the likelihoods of success of risky actions, e.g., an operation, the purchase of stocks. While in the above-mentioned study the two possible resulting states-success or failure-of the action were specified, only desirable (future) states were used as stimulus material in the present study.

Lamm, et al. (1970) suggest that the reported increase in pessimism can 
be explained as follows. The group discussions concentrate predominantly on conditions which coild hinder success (instead of on conditions which further success). Probably, such an orientation is likely to be induced only when the subjects are confronted with the threatening consequences of failure, e.g., death caused by an operation, loss of a fortune through the purchase of stocks. The group behavior was "rational" to a certain extent (in the broader sense of the word) when looking for arguments supporting a more pessimistic assessment. This way, excessive optimism and its possible (although fictional) negative consequences-a choice of action with undesirable results-could be avoided. In the present study, the motive for group participants to favor more pessimistic arguments, which would lead to higher pessimism, was removed since negative consequences of risky action do not apply in the stimulus material. These considerations suggest that the phenomenon of group-induced pessimism is limited only to the judgment of actions in which success or failure are the altermative consequences.

\section{REFERENCES}

ALLPORT, F. H. Social psychology. New Yurk: Houghton Mifflin, 1924.

ANDREWS, I. R., \& JOHNSON, D. I. Small group polarization of judgments. Psychonomic Science, 1971, 24, 191-192.

CVETKovich, G., \& BAUMGARTNER, ST. R. Attitude polarization: the relative influence of discussion group structure and reference group norms. Journal of Personality and Social Psychology, 1973, 26, 159-165.

Dorss, $W$. Intergroup relations and polarization of individual and collective judgments. Journal of Personality and Social Psychology, 1969, 12, 136-143.

DoISE, W. An apparent exception to the extremization of collective judgments. European Journal of Social Psychology, 1971, 4, 511-518.

FRASER, C., GoUge, C., \& BILLIG, M. Risky shifts, cautious shifts, and group polarization. European Journal of Social Psychology, 1971, 1, 7:30.

GOUGE, C., \& FRASER, C. A further demonstration of group polarization. European Journal of Social Psychology, 1972, 2, 95-97.

KOGAN, N., \& WALIACH, M. A. Risk taking: a study in cognition and personality. New York: Holt, Rinchart \& Winston, 1964.

KOGAN, N., \& WALLACH, M. A. Modification of judgmental styie through group interaction. Journal of Personality and Social Psychology, 1966, 4, 165-174.

LAMM, H., TROMMSDORFF, G., \& KOGAN, N. Pessimism-optimism and risk taking in individual and group contexts. Journal of Personality and Social Psycbology, $1970,15,366-374$.

LAMM, H., TromMSDORFF, G., \& ROST-SCHAUde, E. Group-induced extremization: review of evidence and a minority-change explanation. Psychological Reports, 1973, $33,471-484$.

MCCAULEY, C. R., JR. Extremity shifts, risky shifts and attitude shifts after group discussion. European Journal of Social Psycbology, 1972, 2, 417-436.

MoscovicI, S., DoISE, W., \& DULONG, R. Studies in group decision: II. Differences of positions, differences of opinion and group polarization. European Journal of Social Psycbology, 1972, 2, 385-399.

Moscovicr, S., \& IECUYER, R. Studies in group decision: I. Social space, patterns of communication and group consensus. European Journal of Social Psycbology, 1972, 2, 221-244.

MOsCOVICI, S., \& NÈVE, P. Studies on polarization of judgments: III. Majorities, minorities and social judgments. European Journal of Social Psychology, 1973, 3, 479484. 
MoscovicI, S., \& ZaVAlloni, M. The group as a polarizer of attitudes. Journal of Personality and Social Psychology, 1969, 12, 125-135.

Moscovicr, S., ZAVALLONI, M., \& LOUIS-GUÉRIN, C. Studies on polarization of judgments: I. Group effects on person perception. European Journal of Social $P_{s y}$. chology, 1972, 2, 87-91.

Moscovici, S., ZavalloNi, M., \& Weinberger, M. Studies on polarization of judgments: II. Person perception, ego involvement and group interaction. European Journal of Social Psycbology, 1972, 2, 92-94.

MYERS, D. G., \& BISHOP, G. D. Discussion effects on racial attitudes. Science, 1970, $169,718.719$.

MYERS, D. G., \& BISHOP, G. D. Enhancement of dominant attitudes in group discussion. Journal of Personality and Social Psycbology, 1971, 20,386-391.

PAICHELER, G., \& BOUCHET, J. Attitude polarization, familiarization and group process. European Journal of Social Psychology, 1973, 3, 83-90.

RABBIE, J. M., \& VISSER, L. Bargaining strength and group polarization in intergroup negotiations. European Journal of Social Psychology, 1972, 2, 401-416.

SHERIF, M. A study of some social factors in perception. Archives of Psychology, 1935, 27, No. 187.

UPMEYER, A., \& SCHREIBER, W. K. Effects of agreement and disagreement in groups on recognition memory performance and confidence. European Journal of Social Psychology, 1972, 2, 109-128.

Accepted September 5, 1974. 